\title{
Análisis interdimensional de los impactos ambientales, asociados con el botadero a cielo abierto de la ciudad de Quibdó, Colombia
}

\section{Interdimensional analysis of environmental impacts associated with the open-air dump in the city of Quibdo, Colombia.}

\section{Teófilo Cuesta Borja*}

\section{RESUMEN}

Se presenta un análisis interdimensional del impacto ambiental asociado con el botadero a cielo abierto de Quibdó, Colombia, con el fin de aportar recomendaciones, como insumos para la gestión integral de los residuos sólidos en el ámbito local. La metodología aplicada, es la propuesta por Ángelet al. (2001), la cual se denomina modelo analitico por dimensiones y propone una matriz de doble entrada para la identificación y descripción de los impactos ambientales, mediante un cruce interdimensional. Entre los resultados encontrados se encuentran los impactos sobre la biodiversidad, el suelo, el agua, el aire y la sociedad. Como conclusión se puede decir que el modelo analitico por dimensiones es pertinente para el análisis del impacto ambiental en botaderos a cielo abierto; permite aplicar la visión ambiental compleja. Sin embargo, la propuesta de modelo, tal como está formulada es incompleta, en tanto que no profundiza en la evaluación y análisis del impacto ambiental.

Palabras clave: Impacto ambiental; Residuos sólidos; Botadero a cielo abierto; Gestión ambiental; Red de impactos.

\section{SUMMARY}

This article consists of in an interdimensional analysis of the environmental impact associated to the land fill "Marmolejo" of the city of Quibdo, Choco, Colombia, with the purpose of contributing recommendations, as elements for the integral management of the solid waste in the local scope. The methodology applied in the development of the work, is the proposal by Angel et al. (2001), which is denominated: analytical model by dimensions and proposes a matrix of double entrance for the identification and description of the environmental impacts, by means of a interdimensionalcrossing. The results found in the study are diverse, for example: impacts on the local biodiversity, water, soil, air and society. As conclusion, can be said that the analytical model by dimensions is pertinent for the analysis of the environmental impact in landfill; it allows to apply the complex environmental vision. However, the model proposal, as it is formulated is incomplete, whereas it does not deepen in the evaluation and analysis of the environmental impact.

Keywords: Environmental impact; Solid waste; Landfill;

Environmental management; Solid waste; Network of impacts.
* Subdirector de Investigaciones, Instituto de Investigaciones Ambientales del Pacífico "John Von Newmann".

e-mail: tcuesta@iiap.org.co

Recibido: Diciembre 15, 2007

Aceptado: Mayo 17, 2008 


\section{INTRODUCCIÓN}

El continuo aumento de la población y el cambio en las costumbres alimenticias y de consumo en las últimas décadas ha producido un considerable aumento de residuos sólidos urbanos, siendo su composición cada vez más heterogénea. En el mundo, la disposición de residuos está en una situación de emergencia causada por una insuficiente coordinación en la gestión y manejo de los recursos naturales.

Colombia es un país que ha vivido y vive la problemática relacionada con la gestión de los residuos sólidos, muy a pesar de los valiosos esfuerzos de política y de normatividad que se han realizado en los últimos años. La Ley 99 de 1993, marca una nueva era en la concepción de la problemática ambiental del país con la definición de los fundamentos de la política ambiental en torno al desarrollo sostenible. El desarrollo de la gestión ambiental en el contexto de estos nuevos fundamentos permite identificar la necesidad de orientar los esfuerzos hacia la solución de la problemática ambiental generada en los centros urbanos, donde se encuentra asentada más de $70 \%$ de la población colombiana (MAVDT, 2002).

Pese a que para la cuidad de Quibdó no existen datos demográficos confiables, se considera que esta capital bordea los 180 mil habitantes, cifra que es muy dinámica, en virtud del fenómeno del desplazamiento forzoso a causa de la violencia en Colombia y específicamente en el departamento del Chocó. En ese orden de ideas, según datos de CODECHOCÓ (2004), dicha población produce alrededor de 50 toneladas de residuos sólidos por día, cantidad que multiplicada por 30 días del mes equivale a 1.500 toneladas/mes. Sin embargo, tan sólo se reciclan 157 toneladas/mes. Al comparar estas cifras (cantidad de residuos producidos vs. reciclaje), y tomando en cuenta que la ciudad no tiene un relleno sanitario para la disposición final de sus residuos sólidos (sólo dispone de un botadero a cielo abierto), y no tiene la capacidad logística para recolectar y dar tratamiento adecuado al 100\%, es claro que Quibdó presenta un problema de contaminación ambiental de grandes proporciones.

Con esta investigación se pretende poner de relieve la problemática ambiental generada a partir de la disposición inadecuada de los residuos municipales en la ciudad de Quibdó, a través de la aplicación de la metodología de análisis de impacto ambiental por dimensiones (AIAD) propuesta por Ángel et al. (2001). Además, el análisis interdimensional se fortalecerá con base en los postulados de la visión ambiental compleja, impulsada por Morin, Odum, Bermúdez, Noguera, entre otros autores. Sin embargo, es bueno aclarar que el modelo analítico por dimensiones no presenta antecedentes en cuanto al análisis del impacto ambiental en el tema de los residuos sólidos urbanos, por tanto, este esfuerzo, se convierte en una experiencia piloto, a partir de la cual se podrían lograr aportes para fortalecer el modelo.

\section{ÁREADEESTUDIO}

Según datos de González (2003), el municipio de Quibdó, cuya cabecera municipal (Quibdó) es a su vez la capital del departamento del Chocó, está ubicado en la región natural de la costa Pacífica a $43 \mathrm{msnm}$, sobre la margen derecha del río Atrato; se encuentra a $5^{\circ} 41^{\prime} 16^{\prime \prime}$ de latitud norte y a $3^{\circ} 35^{\prime}$ $05^{\prime}$ "de longitud oeste con respecto al meridiano de Bogotá. Quibdó es una población que existe desde el siglo XVI y surgió con el nombre de San Francisco de Quibdó, en honor al Cacique "Quibdó»; su fundador fue el comerciante minero Manuel Cañizales en el mes de agosto del año 1654.

Quibdó limita al norte con los municipios de Bojayá (Chocó) y Urrao (Antioquia), por el oriente limita con Urrao (Antioquia) y Carmen de Atrato (Chocó), por el sur con los municipios de Tadó e Itsmina (Chocó) y por el occidente con el Alto Baudó, Pie de Pató (González 2003). Relata el mismo autor que el corredor Pacífico es habitado por $90 \%$ de población afrocolombiana, y aunque no hay datos precisos para establecer la composición étnica local, es innegable la influencia de población afro en la cotidianidad de Quibdó.

\section{MÉTODOS}

Fase 1: Revisión de información temática y conceptual. El ejercicio de revisión de información temática y conceptual estuvo orientado a obtener el máximo de información generada a partir de estudios socioeconómicos, técnicos y ambientales tanto en el ámbito local y regional como en el nacional e internacional. En ese sentido, se gestionó información, mediante cartas formales a la Corporación Autónoma Regional para el Desarrollo Sostenible del Chocó (CODE- 
CHOCÓ), a la Universidad Tecnológica del Chocó(UTCH), a las Empresas Públicas Municipales del Municipio de Quibdó (EPQ), al Instituto de Investigaciones Ambientales del Pacífico (IIAP), a la Secretaría de Planeación Municipal, a la Secretaria de Agricultura y Medio Ambiente del Departamento del Chocó, a la Dirección de Salud del Departamento del Chocó(DASALUD), a la Secretaría de Salud Municipal y demás instituciones que realizan investigaciones en el municipio de Quibdó. Además, se gestionó información en Internet, en bases de datos especializadas y en bibliotecas.

Fase 2: Visitas técnicas al botadero a cielo abierto. Durante el desarrollo del trabajo, se llevaron a cabo dos visitas de campo, a partir de las cuales se obtuvo información y elementos técnicos para fortalecer la dimensión analítica del estudio. Para realizar dichas visitas de campo se requirió de la conformación de un equipo técnico e interdisciplinario, el cual permitió analizar la situación ambiental del botadero a cielo abierto desde varios ángulos; dicho equipo técnico estuvo integrado por las siguientes disciplinas: ingeniería agronómica, biología con énfasis en recursos naturales y antropología.

Fase 3: Identificación y análisis de los impactos ambientales por dimensiones. La identificación de los impactos ambientales asociados con el botadero a cielo abierto de la ciudad de Quibdó, consistió en relacionar los diferentes impactos ambientales sobre el agua, el suelo, el aire, la flora, la fauna y la sociedad. Por su parte, el análisis de dichos impactos por dimensiones consistió en construir una matriz de doble entrada y cruzar las dimensiones.

Además del ejercicio de cruce interdimensional de los impactos ambientales asociados con el botadero a cielo abierto de la ciudad de Quibdó, se construyó una red de impactos (Figura 1), donde se presentan las relaciones de causa-efecto entre los mismos impactos. Para realizar este ejercicio el responsable de la investigación convocó el mismo equipo técnico que realizó las visitas de campo, quien se encargó de dar una inducción previa a este equipo interdisciplinario, respecto a la metodología a seguir durante el ejercicio (modelo analítico del impacto ambiental por dimensiones).

Fase 4: Conclusiones y recomendaciones para la gestión integral de los residuos sólidos municipales. La formulación de recomendacio- nes para la gestión integral de los residuos sólidos en la ciudad de Quibdó, se hizo en el ejercicio de análisis interdisciplinario, para lo cual se contó con el mismo equipo técnico presentado en líneas anteriores.

\section{RESULTADOS YDISCUSIÓN}

Análisis interdimensional del impacto ambiental y propuestas de intervención. Con base en la información de línea base que se logró obtener a partir de la revisión de la escasa información secundaria y las visitas con un equipo de expertos al botadero a cielo abierto de la ciudad de Quibdó y su área de influencia, se estableció una serie de impactos ambientales, a través del análisis matricial propuesto por Ángel et al. (1996) y mejorado por los mismos autores en la edición del año 2001. A continuación, se presentan los resultados del análisis interdimensional de los impactos ambientales identificados; luego de cada matriz en la que cada dimensión se cruza con si misma y con las otras dimensiones, se presenta una propuesta de intervención desde la dimensión en análisis.

1. Propuesta de intervención desde la dimensión física. La dimensión física en este ejercicio analítico está representada por el volumen de residuos sólidos que genera la ciudad de Quibdó, el cual asciende a 50 toneladas diarias, es decir, 1.500 toneladas / mes. Tomando en cuenta que la ciudad no tiene infraestructura y logística necesaria para recolectar, dar tratamiento y hacer la adecuada disposición final de dichos residuos, estos son llevados parcialmente a un botadero a cielo abierto que por su condición no ofrece las garantías necesarias para evitar los diferentes impactos en recursos como el suelo, el agua, el aire, el bosque, la fauna, el paisaje y la sociedad. A continuación, se presentan las acciones de tipo político y técnico:

a. Decisiones politicas: Implementar el plan de gestión integral de los residuos sólidos (PGIRs). Para lograr cristalizar esta propuesta, se requiere del concurso de varios actores de la ciudad; en primer lugar la autoridad ambiental (CODECHOCÓ), la Universidad Tecnológica del Chocó, el Instituto de Investigaciones Ambientales del $\mathrm{Pa}-$ cífico, el Servicio Nacional de Aprendizaje (SENA), las organizaciones no gubernamentales, la Alcaldia Municipal, la Contraloría, la Procuraduría, las Juntas de Acción Comunal y especialmente la 
sociedad civil.

b. Decisiones técnicas: En cuanto a las acciones técnicas, es preciso realizar un diagnóstico integral de los residuos sólidos en la ciudad, a partir del cual se logre una caracterización de los mismos y de esta forma contar con los insumos necesarios para la definición del PGIRs municipales. De igual forma, se requiere realizar un trabajo técnico que involucra la evaluación técnica en campo para determinar la idoneidad del sitio donde se encuentra el actual botadero a cielo abierto en aras de establecer la viabilidad de una posible transición del botadero hacia un relleno sanitario que cumpla con los parámetros técnicos y legales para la adecuada disposición final de los residuos sólidos municipales. En caso de que el actual botadero no sea viable para la transición plateada, se evaluarán otros sitios hasta encontrar el más apropiado. Después de la evaluación técnica de campo, es preciso proceder con el diseño del relleno sanitario y definir un plan de operación del mismo, considerando una propuesta de cierre técnico al agotar su vida útil.

Finalmente, es importante que la política municipal para la gestión integral de los residuos, cuente con la apropiación presupuestal suficiente para la adquisición de las tecnologías necesarias para garantizar la recolección, manejo y disposición final de los residuos. Además, se requiere capacitar el recurso humano que permita la operativización de dicha política pública municipal e implementar un programa de educación ambiental en la ciudad, dando mucha prioridad a las instituciones educativas de todos los niveles (Tabla 1).

2. Propuesta de intervención desde la dimensión biótica. En aras a recuperar las especies de flora y fauna que han migrado por la presencia del botadero a cielo abierto de la ciudad de Quibdó, se requiere emprender campañas de reforestación en los alrededores del botadero, lo cual implica recuperación directa de especies de flora y fauna que regresarian por la recuperación de su hábitat natural. Asimismo, es importante contemplar la posibilidad de recuperar los ecosistemas acuáticos, a través de actividades de destaponamiento y obras de ingeniería que eviten la llegada de contaminantes a estos ecosistemas. Con la recuperación de los cuerpos de agua, automáticamente se promueve el retorno y mantenimiento de las diferentes formas de vida asociadas con estos ecosistemas.
De igual forma, la transición del botadero a cielo abierto hacia un relleno sanitario, disminuiría la presencia de especies animales que actúan como vectores de enfermedades del ser humano. En ese contexto, se requiere realizar campañas de fumigaciones para mitigar la presencia de vectores en la ciudad; además del tratamiento biológico de los desechos en el botadero a cielo abierto que consiste en la aplicación de microorganismos eficaces (EM), como fermentadores-descomponedores de la materia orgánica, lo cual disminuiría los malos olores y por consiguiente las especies de gallinazos que frecuentan el lugar.

Por otra parte, es muy conveniente que las instituciones encargadas de la gestión ambiental en la zona, especialmente CODECHOCÓ, tomen cartas en el asunto de los desechos sólidos, a través de actos administrativos que promuevan la conservación de la biodiversidad y de los ecosistemas en general. En ese contexto, también se requiere de mayores acciones de control y vigilancia por parte de las autoridades ambientales y policiales para evitar el mal manejo de los recursos bióticos (Tabla 2).

3. Propuesta de intervención desde la dimensión sociocultural. Las acciones de intervención desde la dimensión sociocultural, serían principalmente desde la educación ambiental, lo cual permitiría mejorar los patrones de consumo, fortalecería la cultura de reducción de los residuos en la fuente, la separación de los residuos en la fuente, el reuso de los residuos y el reciclaje. Por otra parte, se promoveria una conciencia ambiental que sin lugar a dudas afectaría positivamente una eventual politica pública de gestión integral de los residuos municipales.

Se requiere también una conciencia y autoreconocimiento de los inmensos valores de las culturas presentes en Quibdó y en la región y de la invaluable riqueza ambiental y natural que es sujeto de respeto y protección, incluso a nivel planetario. Un plan de manejo integrado de residuos sólidos, contribuye a la sostenibilidad de esta riqueza (Tabla 3).

4. Propuesta de intervención desde la dimensión económica. Las acciones de intervención desde la dimensión económica deberá darse a dos niveles; un primer nivel tendría que ser necesariamente la gestión de recursos por parte de la Corporación Autónoma regional, el Municipio y el Departamento para garantizar las obras de 
un relleno sanitario y las tecnologías y logística necesaria para la recolección, tratamiento y disposición adecuada de los residuos municipales. Para el municipio y los demás entes públicos es necesario analizar el potencial económico y de mercado que puede tener el uso adecuado de los residuos sólidos. Por otra parte, se requiere de una propuesta para el fortalecimiento de las dinámicas empresariales alrededor del tema de los desechos. En ese contexto, es preciso fortalecer la estrategia de aprovechamiento de los residuos, a partir de la adquisición de nuevas tecnologias que permitan mayor eficiencia en los procesos de reciclaje de los materiales; de igual forma, se deben dinamizar los procesos asociativos a través del empresarismo solidario. Para ello, se requiere de una negociación política con las entidades financieras para definir líneas de créditos blandos que aumenten la capacidad de inversión de los microempresarios (Tabla 4).

5. Propuesta de intervención desde la dimensión politica. Las acciones desde la dimensión política deberian estar direccionadas fundamentalmente en la definición de una politica pública municipal para la gestión integral de los residuos. En ese sentido, se requiere convocar a los actores principales de la ciudad, bajo el liderazgo intransferible de la administración municipal (alcaldia).

Además, son importantes los esfuerzos de los congresistas del departamento del Chocó y senadores "amigos", para lograr que el gobierno nacional direccione recursos para atender la problemática ambiental de la ciudad, asociada con los residuos municipales. Finalmente, es indispensable solicitar la asesoría directa del Ministerio de Ambiente, Vivienda y Desarrollo Territorial (MAVDT) en los procesos de definición del plan de gestión integral de los residuos municipales y en el diseño técnico de las obras civiles requeridas para la implementación del plan (Tabla 5).

Red de impactos. El modelo analítico por dimensiones propuesto por Ángel et al. (2001), contempla la construcción de una red de impactos que permite ver las interrelaciones entre los mismos, como una manera ordenada de sus características, magnitud e importancia. A continuación, se presenta una red de impactos que surge del análisis interdisciplinario con el grupo de expertos que aportaron a este proyecto (Figura 1).

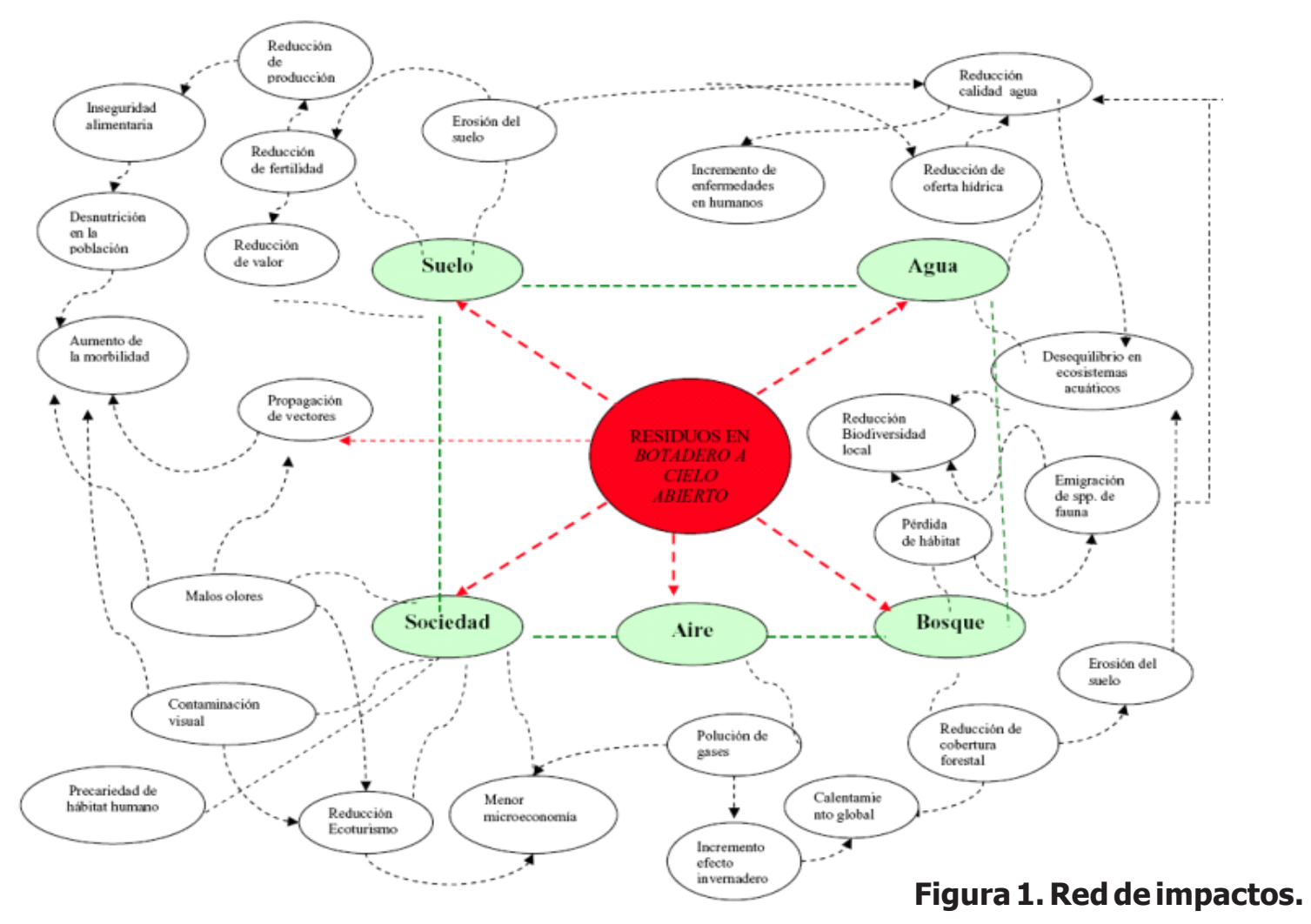


Tabla 1

Análisis interdimensional del impacto ambiental, desde la dimensión física (A)

Física

Biótica

La inadecuada disposición de los residuos sólidos de la ciudad de Quibdó en el botadero a cielo abierto, ocasiona contaminación del aire, a raíz de las emisiones dañinas y gases de efecto invernadero que se generan, como por ejemplo: metano, amoníaco, entre otros.
Económica

La ubicación del botadero a cielo abierto en medio del bosque muy húmedo tropical, afecta los niveles de biodiversidad en la zona, puesto que el botadero crece de manera desordenada y para ello se requiere de talar árboles y demás especies de flora. Todo lo anterior reduce significativamente los niveles de biodiversidad en la zona.
A raíz de la inadecuada disposición de residuos sólidos en el botadero a cielo abierto de la ciudad, se ha generado un sector de empresas informales encargadas de seleccionar en campo materiales que luego son vendidos en el mercado local y en la ciudad de Medellín.
La disposición de 50 toneladas diarias que produce la ciudad, sin ningún tratamiento previo y peor aún en un espacio físico como el que representa el botadero a cielo abierto, genera contaminación visual y ocasiona un drástico cambio en el paisaje.

La incorrecta disposición de los residuos sólidos en el botadero a cielo abierto en una zona con una pluviosidad superior a los 10 mil milímetros anuales, facilita la lixiviación de compuestos contaminantes que surgen en el proceso de descomposición de los residuos y por consiguiente, estos van a parar a los cuerpos de agua de la zona, afectando la seguridad hídrica en términos de la calidad.

La disposición desordenada de los residuos sólidos en el botadero a cielo abierto, ha ocasionado el taponamiento y disminución del caudal de la quebrada la Aguatá que colinda con el botadero.
La disposición de residuos en el lugar instalado para tal fin, atrae especies de aves en grandes poblaciones, lo que ocasiona el desplazamiento de otras especies propias de dicho hábitat. En consecuencia hay reducción de los niveles de biodiversidad de fauna.

La presencia de residuos de todo tipo en el botadero, favorece la propagación de especies animales tales como roedores, insectos y demás vectores de enfermedades humanas.

Los lixiviados que surgen del botadero a cielo abierto, llegan a los cuerpos de agua, afectando la permanencia de especies ícticas y demás fauna asociada al ciclo vital acuático.

\section{El ingreso de la maquinaria} transportadora y compactadora de los residuos sólidos al botadero a cielo abierto, ocasiona la emigración de especies animales, debido al ruido y las vibraciones que produce la ésta.
A pesar de que existe un gran potencial para el reciclaje de materiales residuales en la ciudad de Quibdó, a la fecha no existe la infraestructura ni la tecnología adecuada para tal fin. En ese contexto, se reporta subexplotación de dicho potencial empresarial.

La ubicación del botadero a cielo abierto en la carretera Quibdó-Tutunendo-Medellín, ocasiona una reducción de la actividad turística de la localidad de Tutunendo.

\section{Sociocultural}

La alta generación de residuos en el ámbito urbano y ante la poca capacidad de las empresas públicas para ofrecer e servicio de recolección y tratamiento de los mismos, surge una problemática de acumulación de los residuos en las calles de la ciudad por varios días. Lo anterior, representa un problema

para la comunidad. En la medida en que se generan malos olores, la reproducción de vectores de enfermedades humanas y en general problemas de salud pública.

La mala disposición y falta de tratamiento de los residuos sólidos urbanos en el botadero a cielo abierto, ocasiona malos olores y por consiguiente afectación los transeúntes de la carretera Quibdó-Medellín, ya que dicho botadero se encuentra al borde la misma.

La ubicación del botadero a cielo abierto, genera una situación en los vecinos de la zona que tiene sus huertos agrícolas, debido a que éstos creen que los lixiviados y demás contaminantes que genera el botadero contaminan sus cultivos y por esa razón tienen recelos de consumir sus productos. Lo anterior atenta contra la seguridad alimentaria de los pobladores.

\section{Política}

La existencia del botadero a cielo abierto de la ciudad de Quibdó, actualmente representa una violación a la legislación colombiana y específicamente al decreto 1045 de 2003, el cual establece que para el 2005 todos los botaderos deberían convertirse en rellenos sanitarios
La presencia del botadero a cielo abierto de la ciudad de Quibdó con todos los problemas ambientales y sociales asociados a éste, podría generar movilizaciones cívicas en contra de las autoridades ambientales y en contra del Estado.

Poca gestión del municipio para mejorar los procesos de recolección, manejo y disposición final de los residuos; de tal forma que llegase la mínima cantidad posible de estos al botadero. Falta de intervención de las instituciones, organizaciones comunitarias y autoridades responsables de la gestión ambiental, en aras a garantizar las condiciones adecuadas para el manejo de los desechos municipales. a ubicación actual de botadero a cielo abierto de la ciudad de Quibdó afecta negativamente el valor de la propiedad y de la tierra, lo cual es muy importante en la medida en que dicha zona representa una de las áreas de expansión de la ciudad.
La existencia del botadero a cielo abierto de la ciudad de Quibdó, ha generado organizaciones empresariales monopolistas, hasta el punto en que actualmente, la posibilidad de hacer negocio a partir de los materiales de reciclaje, es una situación de conflicto social, por cuanto no se le permite el ingreso a nuevos recicladores a la zona. 
Bioetnia Volumen 5 No 1 (enero-junio), 2008

Tabla 1

Análisis interdimensional del impacto ambiental, desde la dimensión física (B)

\begin{tabular}{|c|c|c|c|c|}
\hline Física & Biótica & Economía & Sociocultural & Política \\
\hline $\begin{array}{l}\text { Durante la ruta de } \\
\text { recolección de los } \\
\text { residuos y el transporte } \\
\text { al botadero a cielo } \\
\text { abierto, se esparcen } \\
\text { residuos sólidos en calles } \\
\text { y carreteras, generando } \\
\text { así contaminación visual } \\
\text { y por malos olores. }\end{array}$ & & $\begin{array}{l}\text { La falta de iniciativa para } \\
\text { aprovechar los residuos sólidos } \\
\text { orgánicos que se generan en la } \\
\text { ciudad de Quibdó, genera } \\
\text { pérdidas económicas para las } \\
\text { empresas públicas, para los } \\
\text { recicladores y para ciudad en } \\
\text { sí. }\end{array}$ & $\begin{array}{l}\text { En la medida en que no se } \\
\text { solucione el problema del } \\
\text { botadero a cielo abierto y se } \\
\text { de la transición entre el } \\
\text { botadero y el relleno sanitario, } \\
\text { es posible que la situación } \\
\text { genere un problema sanitario } \\
\text { de grandes proporciones en la } \\
\text { ciudad. La anterior previsión, } \\
\text { surge a partir de que le } \\
\text { ministerio de ambiente cerrará } \\
\text { el botadero tarde que temprano } \\
\text { a través de } \\
\text { CODECHOCó. }\end{array}$ & \\
\hline $\begin{array}{l}\text { La expansión del } \\
\text { botadero a cielo abierto, } \\
\text { ocasiona la remoción de } \\
\text { suelo, lo cual ocasiona la } \\
\text { erosión del mismo } \\
\text { debido a los altos niveles } \\
\text { de precipitación en la } \\
\text { zona. Finalmente, hay } \\
\text { contaminación de } \\
\text { cuerpos de aguas por los } \\
\text { sedimentos. }\end{array}$ & & $\begin{array}{l}\text { La falta de proceso de } \\
\text { separación de los residuos } \\
\text { sólidos urbanos en la fuente, } \\
\text { afecta negativamente la } \\
\text { actividad económica del } \\
\text { reciclaje. } \\
\text { A pesar de que los usuarios del } \\
\text { servicio de aseo en la ciudad } \\
\text { de Quibdó pagan por la tasa de } \\
\text { aseo, no se les garantiza } \\
\text { calidad en el mismo. Esta } \\
\text { situación se configura como un } \\
\text { típico engaño a la sociedad } \\
\text { quibdoseña. }\end{array}$ & & \\
\hline \multicolumn{5}{|l|}{$\begin{array}{l}\text { La falta de maquinaria } \\
\text { especializada para el } \\
\text { procesamiento de los } \\
\text { residuos en el botadero a } \\
\text { cielo abierto, ocasiona } \\
\text { menor eficiencia en el } \\
\text { uso del espacio y por } \\
\text { consiguiente aumenta la } \\
\text { utilización de suelo }\end{array}$} \\
\hline $\begin{array}{l}\text { La inadecuada disposi- } \\
\text { ción de los residuos } \\
\text { sólidos en el botadero a } \\
\text { cielo abierto ocasiona } \\
\text { contaminación del suelo, } \\
\text { a causa de metales } \\
\text { pesados y demás } \\
\text { compuestos químicos } \\
\text { que afectan dicho } \\
\text { recurso. }\end{array}$ & & & & \\
\hline
\end{tabular}


Tabla 2

Análisis interdimensional del impacto ambiental, desde la dimensión biótica

\begin{tabular}{|c|c|c|c|c|}
\hline Física & Biótica & Economía & Sociocultural & Política \\
\hline $\begin{array}{l}\text { Las aves que viven en } \\
\text { torno al botadero a cielo } \\
\text { abierto, se desplazan } \\
\text { ocasionalmente a otras } \\
\text { zonas, llevando consigo } \\
\text { contaminantes que } \\
\text { pueden dispersarse y } \\
\text { ocasionar peligros a la } \\
\text { sociedad. }\end{array}$ & $\begin{array}{l}\text { La propagación de } \\
\text { roedores e insectos y } \\
\text { la llegada de especies } \\
\text { de aves de rapiña al } \\
\text { lugar donde se } \\
\text { encuentra el botadero } \\
\text { a cielo abierto, } \\
\text { ocasiona la migración } \\
\text { de otras especies de } \\
\text { fauna, por el fenómeno } \\
\text { de la competencia } \\
\text { territorial. }\end{array}$ & $\begin{array}{l}\text { La propagación de roedores } \\
\text { e insectos plagas a raíz del } \\
\text { botadero a cielo abierto, } \\
\text { ocasiona una afectación } \\
\text { directa a los sistemas } \\
\text { agropecuarios de la } \\
\text { localidad, se reducen las } \\
\text { cosechas y por consiguien- } \\
\text { te los ingresos se ven } \\
\text { afectados negativamente. }\end{array}$ & $\begin{array}{l}\text { El proceso de descomposi- } \\
\text { ción de los residuos sólidos, } \\
\text { ocasiona la propagación de } \\
\text { insectos y roedores, los } \\
\text { cuales se convierten en } \\
\text { vectores de afectacióna la } \\
\text { población local. }\end{array}$ & $\begin{array}{l}\text { La Afectación de los niveles } \\
\text { de biodiversidad, a raíz } \\
\text { de la presencia del botadero } \\
\text { a cielo abierto, constituye } \\
\text { una auténtica viola-ción a la } \\
\text { legislación colombiana en } \\
\text { materia ambiental y } \\
\text { de protección a la } \\
\text { biodiversidad. }\end{array}$ \\
\hline $\begin{array}{l}\text { La presencia de roedores } \\
\text { en los alrededores del } \\
\text { botadero a cielo abierto, } \\
\text { ocasiona que éstos } \\
\text { construyan grandes } \\
\text { galerías en el suelo, } \\
\text { favoreciendo así procesos } \\
\text { erosivos y degradación } \\
\text { del recurso. }\end{array}$ & $\begin{array}{l}\text { La dominancia de } \\
\text { algunas especies de } \\
\text { fauna en el botadero a } \\
\text { cielo abierto, ocasiona } \\
\text { el espantamiento y la } \\
\text { emigración de otras } \\
\text { especies, y por } \\
\text { consiguiente se rompen } \\
\text { eslabones tróficos. }\end{array}$ & $\begin{array}{l}\text { La disminución de los } \\
\text { niveles de biodiversidad en } \\
\text { la zona donde se encuentra } \\
\text { el botadero a cielo abierto, } \\
\text { representa una reducción } \\
\text { directa del potencial de uso } \\
\text { de los recursos bióticos en } \\
\text { la zona. }\end{array}$ & $\begin{array}{l}\text { La presencia de roedores e } \\
\text { insectos plagas, afecta los } \\
\text { sistemas } \\
\text { agropecuarios locales y por } \\
\text { tanto la seguridad } \\
\text { alimentaria de la población. }\end{array}$ & $\begin{array}{l}\text { La propagación de roedores e } \\
\text { insectos plagas en la locali- } \\
\text { dad, podría generar protestas } \\
\text { y movilizaciones cívicas. }\end{array}$ \\
\hline $\begin{array}{l}\text { La propagación de } \\
\text { roedores e insectos } \\
\text { acelera el proceso de } \\
\text { degradación de los } \\
\text { residuos sólidos, por } \\
\text { consiguiente habrá mayor } \\
\text { transferencia hacia la } \\
\text { atmósfera de gases con } \\
\text { efecto invernadero. }\end{array}$ & $\begin{array}{l}\text { La dominancia de } \\
\text { algunas especies } \\
\text { animales, reduce los } \\
\text { niveles de } \\
\text { biodiversidad local. }\end{array}$ & $\begin{array}{l}\text { La presencia de roedores, } \\
\text { insectos y de aves poco } \\
\text { agradables, reduce el valor } \\
\text { de la propiedad de la tierra }\end{array}$ & & \\
\hline $\begin{array}{l}\text { La pérdida de cobertura } \\
\text { vegetal a raíz del } \\
\text { establecimiento y } \\
\text { ampliación del botadero a } \\
\text { cielo abierto, expone el } \\
\text { suelo al fenómeno de la } \\
\text { erosión, con todas las } \\
\text { implicaciones de } \\
\text { contaminación de cuerpos } \\
\text { de agua y afectando la } \\
\text { vida de dichos } \\
\text { ecosistemas acuáticos. }\end{array}$ & $\begin{array}{l}\text { Afectación de algunos } \\
\text { ciclos de vida, debido } \\
\text { al rompimiento de } \\
\text { cadenas tróficas. }\end{array}$ & $\begin{array}{l}\text { El deterioro de los recursos } \\
\text { bióticos en la zona del } \\
\text { botadero, afecta el uso } \\
\text { activo y pasivo de la tierra } \\
\text { que sirve para la } \\
\text { producción, fincas de } \\
\text { descanso y el turismo. }\end{array}$ & & \\
\hline
\end{tabular}


Tabla 3

Análisis interdimensional del impacto ambiental, desde la dimensión sociocultural

\begin{tabular}{|c|c|c|c|}
\hline Física & Biótica & Economía & Política \\
\hline $\begin{array}{l}\text { La creciente población de la } \\
\text { ciudad de Quibdó, debido en } \\
\text { parte al fenómeno del } \\
\text { desplazamiento forzoso, } \\
\text { aumentará significativamente } \\
\text { los volúmenes de producción } \\
\text { de desecho en la ciudad. A } \\
\text { esto se suma el hecho de que } \\
\text { la ciudad aún no está } \\
\text { preparada para hacer una } \\
\text { gestión adecuada de los } \\
\text { mismos. }\end{array}$ & $\begin{array}{l}\text { La poca cultura ambiental de } \\
\text { la población } \\
\text { quibdoseña, ocasiona } \\
\text { contaminación de eco- } \\
\text { sistemas forestales, y } \\
\text { ecosistemas acuáticos, } \\
\text { afectando así la bio- } \\
\text { diversidad en su conjunto. }\end{array}$ & $\begin{array}{l}\text { Los patrones de consumo en } \\
\text { aumento de la sociedad } \\
\text { quibdoseña, aumentan el uso de } \\
\text { los recursos biofísicos y por } \\
\text { consiguiente los niveles de } \\
\text { desechos. El anterior escenario, } \\
\text { representa una ventaja para los } \\
\text { recicladores locales. Sin } \\
\text { embargo, se incrementan los } \\
\text { niveles de desechos y con ello } \\
\text { los niveles de contaminación } \\
\text { potencial. }\end{array}$ & $\begin{array}{l}\text { La población que vive en la } \\
\text { ciudad de Quibdó, estigmatiza a } \\
\text { los pobladores de la zona } \\
\text { periférica de la ciudad donde se } \\
\text { encuentra el botadero a cielo } \\
\text { abierto. Estos últimos son vistos } \\
\text { como ciudadanos sucios y de } \\
\text { segunda por parte de los } \\
\text { pobladores de la ciudad en sí. }\end{array}$ \\
\hline \multirow[t]{2}{*}{$\begin{array}{l}\text { La poca conciencia ambiental, } \\
\text { aunada a la cultura consumista } \\
\text { de la población, magnifica el } \\
\text { problema de contaminación } \\
\text { ambiental por residuos sólidos } \\
\text { en la ciudad y en sus } \\
\text { alrededores. }\end{array}$} & & $\begin{array}{l}\text { Los procesos de capacitación del } \\
\text { recurso humano, que vive de la } \\
\text { economía de los residuos sólidos } \\
\text { en el botadero a cielo abierto, } \\
\text { podría incrementar la eficiencia } \\
\text { de los procesos de reciclaje y } \\
\text { por consiguiente aumentar la } \\
\text { rentabilidad del negocio en la } \\
\text { medida en que se fortalezcan } \\
\text { los procesos organizativos y de } \\
\text { capacitación. }\end{array}$ & $\begin{array}{l}\text { No existe conciencia sobre la } \\
\text { importancia del reciclaje y en la } \\
\text { labor que se puede realizar con } \\
\text { las familias en el manejo de los } \\
\text { desechos domésticos en la } \\
\text { fuente. }\end{array}$ \\
\hline & & $\begin{array}{l}\text { La falta de cultura organizativa, } \\
\text { cooperativa y empresarial en la } \\
\text { ciudad, ha dificultado hacer un } \\
\text { mejor negocio alrededor de los } \\
\text { residuos sólidos que produce la } \\
\text { ciudad. }\end{array}$ & $\begin{array}{l}\text { No existen programas de } \\
\text { educación ambiental, } \\
\text { especialmente en las instituciones } \\
\text { educativas. En ese sentido, es } \\
\text { necesario operativizar los } \\
\text { Proyectos Ambientales Escolares } \\
\text { Sostenibles (PRAES), en aras a } \\
\text { crear conciencia ambiental en la } \\
\text { juventud. }\end{array}$ \\
\hline
\end{tabular}

Tabla 4

Análisis interdimensional del impacto ambiental, desde la dimensión económica

\begin{tabular}{|c|c|c|c|}
\hline Física & Biótica & Economía & Política \\
\hline $\begin{array}{l}\text { La falta de recursos para } \\
\text { inversión, ha dificultado la } \\
\text { transición de un botadero a cielo } \\
\text { abierto a un relleno sanitario con } \\
\text { todas las condiciones técnicas para } \\
\text { le adecuada disposición final de } \\
\text { los residuos sólidos urbanos. }\end{array}$ & $\begin{array}{l}\text { El potencial de uso de los } \\
\text { recursos bióticos de la zona } \\
\text { donde se encuentra el } \\
\text { botadero a cielo abierto podría } \\
\text { verse afectado } \\
\text { negativamente, debido a la } \\
\text { degradación del mismo por la } \\
\text { contaminación ambiental. }\end{array}$ & $\begin{array}{l}\text { La falta de inversión por } \\
\text { parte de las empresas } \\
\text { públicas de la ciudad para } \\
\text { mejorar los procesos de } \\
\text { reciclaje y aprovechamiento } \\
\text { de los residuos, reduce el } \\
\text { potencial de ingresos propios } \\
\text { para la misma empresa. }\end{array}$ & $\begin{array}{l}\text { Las pocas actividades económicas } \\
\text { que se generan alrededor de los } \\
\text { residuos sólidos en el botadero a } \\
\text { cielo abierto de la ciudad de } \\
\text { Quibdó, ha generado conflictos } \\
\text { sociales entre personas } \\
\text { monopolistas y nuevos } \\
\text { recicladores. }\end{array}$ \\
\hline \multirow[t]{2}{*}{$\begin{array}{l}\text { La actividad económica del } \\
\text { reciclaje, aún con pocos } \\
\text { estándares de eficiencia, reduce el } \\
\text { volumen de desechos sólidos en } \\
\text { el botadero a cielo abierto. No } \\
\text { existen suficientes recursos para } \\
\text { investigación que permita el } \\
\text { mejoramiento del MIRS en todas } \\
\text { sus fases. }\end{array}$} & $\begin{array}{l}\text { La poca o casi nula inversión } \\
\text { en protección de los recursos } \\
\text { bióticos, genera una pérdida } \\
\text { irreparable para la sociedad en } \\
\text { sus conjunto. }\end{array}$ & $\begin{array}{l}\text { Alrededor del botadero a } \\
\text { cielo abierto d la ciudad de } \\
\text { Quibdó, desperdician } \\
\text { iniciativas empresariales } \\
\text { alrededor de los residuos } \\
\text { sólidos orgánicos y } \\
\text { favorecer así la producción } \\
\text { agropecuaria limpia. }\end{array}$ & $\begin{array}{l}\text { Los trabajadores del reciclaje no } \\
\text { cuentan con ninguna protección ni } \\
\text { tampoco guardan las mínimas } \\
\text { reglas de seguridad industrial. A } \\
\text { todo lo anterior, se suma la falta } \\
\text { de seguridad social, lo que se } \\
\text { convierte en una auténtica } \\
\text { explotación. }\end{array}$ \\
\hline & & & $\begin{array}{l}\text { Se ha reportado hechos de } \\
\text { racismo y discriminación, debido al } \\
\text { monopolio de la actividad del } \\
\text { reciclaje. }\end{array}$ \\
\hline
\end{tabular}


Tabla 5

Análisis interdimensional del impacto ambiental, desde la dimensión política

\begin{tabular}{|c|c|c|c|c|}
\hline Física & Biótica & Economía & Sociocultural & Política \\
\hline $\begin{array}{l}\text { La aplicación de la } \\
\text { normatividad ambiental } \\
\text { actual (decreto } 1045 \text { de } \\
2003 \text { ), respecto al tema } \\
\text { de los residuos sólidos, } \\
\text { podría ocasionar un } \\
\text { problema sanitario } \\
\text { complejo en la ciudad } \\
\text { de Quibdó, debido al } \\
\text { cierre del botadero a } \\
\text { cielo abierto. }\end{array}$ & $\begin{array}{l}\text { La aplicación de la } \\
\text { normatividad ambiental } \\
\text { en torno al tema de los } \\
\text { residuos sólidos podría } \\
\text { generar protección a los } \\
\text { recursos bióticos. En la } \\
\text { medida en que no se } \\
\text { construya un relleno } \\
\text { sanitario, se generaría } \\
\text { mayor contaminación de } \\
\text { estos recursos, por } \\
\text { cuanto los residuos } \\
\text { estarían dispersos, } \\
\text { afectando así mayor } \\
\text { área. }\end{array}$ & $\begin{array}{l}\text { La aplicación de la norma- } \\
\text { tividad ambiental de los } \\
\text { residuos sólidos, podría } \\
\text { provocar la implementación } \\
\text { de un PGIR's. lo que } \\
\text { ayudaría mucho en los } \\
\text { procesos de reciclaje y } \\
\text { demás dinámicas } \\
\text { económicas alrededor del } \\
\text { eventual relleno sanitario. }\end{array}$ & $\begin{array}{l}\text { La aplicación de la } \\
\text { normatividad } \\
\text { ambiental, respecto a I } \\
\text { adecuado manejo y } \\
\text { disposición final de los } \\
\text { residuos sólidos, } \\
\text { mejoraría el ambiente } \\
\text { de la ciudad y en el } \\
\text { área donde se } \\
\text { encuentra actualmente } \\
\text { el botadero a cielo } \\
\text { abierto. Todo este } \\
\text { escenario, favorecería } \\
\text { la calidad de vida de } \\
\text { los quibdoseños. }\end{array}$ & $\begin{array}{l}\text { La no aplicación de la } \\
\text { normatividad ambiental, } \\
\text { podría generar } \\
\text { movilizaciones cívicas en } \\
\text { contra del botadero a } \\
\text { cielo abierto. }\end{array}$ \\
\hline $\begin{array}{l}\text { La aplicación de la } \\
\text { normatividad ambiental } \\
\text { en torno a los residuos } \\
\text { sólidos, podría generar } \\
\text { mayor protección de } \\
\text { los recursos suelo, agua } \\
\text { y aire. }\end{array}$ & $\begin{array}{l}\text { La voluntad política para } \\
\text { la protección de los } \\
\text { recursos naturales, } \\
\text { permitiría alcanzar un } \\
\text { equilibrio ecológico de los } \\
\text { ecosistemas terrestres y } \\
\text { acuáticos afectados por el } \\
\text { botadero a cielo abierto. }\end{array}$ & $\begin{array}{l}\text { La política de estado, } \\
\text { respecto al micro crédito, } \\
\text { podría mejorar los procesos } \\
\text { empresariales alrededor del } \\
\text { eventual relleno sanitario, } \\
\text { ya que los } \\
\text { microempresarios, podrían } \\
\text { acceder a capital y así } \\
\text { mejorar sus procesos. }\end{array}$ & $\begin{array}{l}\text { Con la implementación } \\
\text { de un relleno sanitario, } \\
\text { en virtud de la } \\
\text { aplicación de la } \\
\text { normatividad } \\
\text { ambiental, podrían } \\
\text { surgir mejores } \\
\text { esquemas organizativos } \\
\text { y empresariales en } \\
\text { torno a los residuos } \\
\text { sólidos urbanos. }\end{array}$ & $\begin{array}{l}\text { El Municipio de Quibdó } \\
\text { es políticamente } \\
\text { vulnerable porque } \\
\text { además de la sanción } \\
\text { social, podría recibir } \\
\text { cargos legales desde } \\
\text { niveles superiores (Ej: } \\
\text { MAVDT, Contraloría, } \\
\text { etc.) que le acarreen } \\
\text { costosas medidas } \\
\text { correctivas. }\end{array}$ \\
\hline \multirow[t]{2}{*}{$\begin{array}{l}\text { La concurrencia de } \\
\text { entes nacionales para } \\
\text { dar apertura a un real } \\
\text { Manejo Integrado de } \\
\text { Residuos Sólidos, } \\
\text { permitiría la concreción } \\
\text { de un relleno sanitario } \\
\text { apropiado para la } \\
\text { ciudad. }\end{array}$} & & $\begin{array}{l}\text { La aplicación de la } \\
\text { normatividad ambiental, } \\
\text { podría aumentar el valor de } \\
\text { la propiedad y la tierra en } \\
\text { la zona donde actualmente } \\
\text { se encuentra el botadero a } \\
\text { cielo abierto. }\end{array}$ & $\begin{array}{l}\text { Con la aplicación de la } \\
\text { normatividad } \\
\text { ambiental, reduciría el } \\
\text { problema de salud } \\
\text { pública asociado a los } \\
\text { residuos sólidos. }\end{array}$ & $\begin{array}{l}\text { La concurrencia de los } \\
\text { entes superiores ha sido } \\
\text { escasa, de modo que el } \\
\text { municipio debe enfrentar } \\
\text { sólo muchos de los } \\
\text { problemas técnicos y } \\
\text { económicos que acarrea } \\
\text { el tema de los residuos. }\end{array}$ \\
\hline & & $\begin{array}{l}\text { La no aplicación de la } \\
\text { normatividad ambiental } \\
\text { respecto al tema de los } \\
\text { residuos sólidos, desactiva } \\
\text { el sector turístico de la } \\
\text { localidad de Tutunendo, } \\
\text { debido a que los turistas se } \\
\text { desmotivan ante un transito } \\
\text { por la carretera con malos } \\
\text { olores y demás aspectos } \\
\text { relacionados con el tema de } \\
\text { los residuos sólidos. }\end{array}$ & & \\
\hline
\end{tabular}

\section{CONCLUSIONES}

- El modelo analítico por dimensiones propuesto por Ângel et al. (2001) y aplicado en este trabajo para el análisis de los impactos ambientales asociados con el botadero a cielo abierto de la ciudad de Quibdó, es pertinente. Sin embargo, se requiere desagregar y además de la dimensión social incluir separadamente la dimensión cultural, en aras de lograr un análisis mucho más completo, dadas las característi- cas culturales de la región chocoana.

- La problemática ambiental de Quibdó, respecto a los residuos sólidos urbanos, sólo se podrá solucionar, partiendo de la formulación y ejecución de un PGIRS, que contemple variables como la educación ambiental, construcción de un relleno sanitario y las demás actividades involucradas en dicho plan, de acuerdo con el Decreto 1045 de 2003.

- El botadero a cielo abierto de la ciudad de Quibdó, presenta mayoritariamente impactos 


\section{Bioetnia Volumen 5 No 1 (enero-junio), 2008}

sobre las dimensiones física, biótica y sociocultural. Las dimensiones económica y politica, son impactadas aunque de modo menos considerable.

\section{RECOMENDACIONES}

Para el manejo de los residuos municipales:

- Lograr la implementación de los PRAES en las instituciones educativas de la ciudad de Quibdó, como una manera de promover un cambio de actitud de estudiantes, profesores y funcionarios.

- Generar espacios de concertación en aras a involucrar a los diferentes actores institucionales, civiles y de gobierno en la construcción de una estrategia que permita visualizar alternativas de solución al problema de los residuos sólidos municipales, en el corto, mediano y largo plazo.

- Implementar el Plan de Gestión Integral de Residuos Sólidos (PGIRS) para la ciudad de Quibdó, en donde se contemple una estrategia de reducción en la fuente, reutilización y reciclaje de materiales residuales.

- Diseñar e implementar un rograma de educación ambiental y de cultura ciudadana, que permita modificar la cultura y las acciones anti-ambientalistas de los vecinos de la ciudad de Quibdó.

- Involucrar a las universidades, al IIAP, a CODECHOCÓ y demás instituciones para que desarrollen estudios, diagnósticos e investigaciones relacionadas con el tema de los residuos sólidos en el municipio de Quibdó y en otras zonas del departamento del Chocó.

\section{Para la disposición final de los residuos} municipales:

- Realizar una evaluación técnica de campo con expertos para determinar la idoneidad del sitio donde se encuentra el botadero en aras a determinar la viabilidad para una transición hacia un relleno sanitario con las características técnicas y jurídicas. Esta evaluación conducirá a la selección de un sitio para implementar el relleno sanitario, tomando en cuenta la opinión de los diferentes actores sociales, en especial las comunidades afectadas.

- Diseñar un relleno sanitario, con base en los parámetros técnicos fijados por el MAVDT. Dicho diseño deberá contemplar áreas de separación de los desechos, reciclaje, tratamiento y disposición final.

\section{Para el modelo analitico por dimensiones:}

- La propuesta de análisis interdimensional del impacto ambiental propuesta por Ángel et al. (2001), requiere ser ajustada para incluir una metodología de evaluación del impacto ambiental, pues el "modelo" propuesto, no profundiza hasta el nivel de cuantificación y valoración económica de los impactos ambientales, sólo se queda en aspectos descriptivos-cualitativos.

- La propuesta planteada a través del modelo analítico por dimensiones, requiere ser ajustada y fortalecida bajo una visión de mayor integralidad, que permita una verdadera comprensión multidisciplinar e interdimensional de los impactos ambientales, asociados con los proyectos de desarrollo y a otras actividades de intervención antrópica.

\section{LITERATURA CITADA}

Angel, E. 2001. Gestión ambientalen proyectos de desarrollo. $3^{\mathrm{a}} \mathrm{ed}$. Medellin; UNALMED.

Angel, E. 1996. Gestión ambiental en proyectos de desarrollo, una propuesta desde los proyectos energéticos. Santa Fe de Bogotá: Fondo FEN.

Corporación Autónoma Regional para el Desarrollo Sostenible del Chocó (CODECHOCÓ ). 2004. Diagnóstico sobre la situación actual de los residuos sólidos en el Chocó. Quibdó: CODECHOCÓ.

Ministerio de Ambiente Vivienda y Desarrollo Territorial (MAVDT). 2004. Reglamento técnico del sector de agua potable y saneamiento básico. Bogotá: MAVDT.

Ministerio de Ambiente Vivienda y Desarrollo Territorial (MAVDT). 2003. Resolución 1045 de 2003 por la cual se establecen los parámetros para los PGIRS. Bogotá: MAVDT.

Ministerio de Ambiente Vivienda y Desarrollo Territorial (MAVDT). 2002. Relleno sanitario. Guía ambiental. Bogotá: MAVDT.

Moreno, C. I. 2002. Hábitat y vivienda con criterio ambiental. En: Miradas al hábitat. Medellín: Escuela de Hábitat. CEHAP, Universidad Nacional de Colombia.

Morin, E. 1990. Science avec conciense. Nouvelle ed. Paris: Editorial Fayard, Col Points. 